\title{
Lassen Volcanic Fumaroles and Hot Springs: Analog for Mars
}

\author{
Lindsay J. McHenry ${ }^{1}$, Teri L. Gerard, Gabrielle L. Walters \\ Department of Geosciences, University of Wisconsin- Milwaukee
}

\begin{abstract}
We are conducting a pilot study on the hydrothermal alteration of lavas at Lassen Volcanic National Park as an analog for potential hydrothermal deposits on Mars. Lassen has hot springs and fumaroles that have altered its lavas into silica, sulfates, and phyllosilicates, all mineral types also identified on Mars. Hydrothermal environments were likely common on Mars (due to evidence of early aqueous and a long record of volcanic activity), and such environments could have remained habitable long after the surface cooled and desiccated. However, some hydrothermal environments are more habitable than others, and being able to distinguish between the deposits of hostile acid-sulfate fumarole and more accommodating near-neutral hot spring environments can provide clues to habitability. Lassen hydrothermal environments produce silica by both acid-sulfate leaching and precipitation from neutral hydrothermal waters, both of which have been suggested as potential origins for deposits in Columbia Hills of Gusev Crater on Mars.
\end{abstract}

\section{Objectives}

The objectives of this study are to:

1. Determine the mineralogical and geochemical patterns of lava alteration associated with acid-sulfate leaching at Lassen hot springs and fumaroles, and contrast them with the patterns associated with more neutral, Cl-rich hydrothermal fluids at fumaroles and hot springs within Lassen park.

2. Compare these results to the mineralogy and geochemistry of hydrothermal deposits observed in the Columbia Hills of Gusev Crater, and determine if either scenario is more consistent with the observations.

3. Determine what mineralogical and geochemical evidence for hydrothermal alteration is most likely to be preserved in the rock record by analyzing samples from the hydrothermally altered lavas of Pleistocene Brokeoff Volcano (in Lassen park) and comparing them to samples from the active fields.

\section{Introduction}

One of the most fascinating discoveries about Mars over the last decade has been the presence of extensive sulfate and phyllosilicate alteration products on its surface, potentially indicating the long-term interaction between liquid water and Mars' volcanic crust (e.g. Bibring et al., 2005; Murchie et al., 2009). This suggests a warmer, wetter Mars during its early history, followed by eventual desiccation and cooling. If life ever emerged on Mars, it likely did so during this early period. However, wet, warm environments conducive to life likely persisted in "hydrothermal" environments associated with volcanic activity long after the surface became inhospitable (Walter \& Des Marais, 1993; Schulze-Markuch et al., 2007). Likely mineralogical and geochemical evidence for hydrothermal activity on Mars has been observed by the Mars Exploration Rover (MER) Spirit at Gusev Crater (e.g. Yen et al., 2008), and through remote sensing from the Mars Reconnaissance Orbiter (MRO, e.g. Ehlmann et al., 2009).

\footnotetext{
${ }^{1}$ The authors would like to acknowledge the Wisconsin Space Grant Consortium for their ongoing financial support of this project, and the National Park Service for granting permission to conduct field research at Lassen Volcanic National Park.
} 
Earth has similar deposits in volcanically active areas, and by studying the active processes and deposits created in diverse terrestrial environments, we can better interpret the context of Martian deposits. What mineralogical and geochemical changes occur when hydrothermal fluids interact with volcanic material? How much of this signature is preserved in the rock record? Can these mineralogical and geochemical alteration patterns be used to determine the nature of the fluids ( $\mathrm{pH}$, temperature, salinity, etc.) involved, which could help determine potential habitability? All of these questions can be addressed through terrestrial analog studies.

We are conducting an analog study on fumarole and hot spring related hydrothermal alteration at Lassen Volcanic National Park in the southern Cascades of California. While the underlying volcanic composition is different from Mars (dacitic, not basaltic), the overall mineralogical and geochemical alteration patterns appear similar, with alunite (an aluminum sulfate), phyllosilicates, and silica. Sampling older, "fossil" hydrothermal deposits within the park (e.g. Pleistocene altered rocks from Brokeoff Mountain: Rose et al., 1994, Crowley et al., 2004; John et al., 2004; Janik and McLaren, 2010) will allow us to examine the long-term preservation potential of this kind of deposit.

\section{Geological Background}

Mount Lassen, in the southern Cascades of Northern California, last erupted in 1914-1915 (Day and Allen, 1925). It has the largest active hydrothermal field in the Cascades, with fumaroles, hot springs, and mud pots (Janik and McLaren, 2010). Volcanic activity in the Lassen area began 825,000 years ago and a series of volcanoes: dacitic Rockland caldera, then andesitic Brokeoff volcano 590,000 years ago, then dacitic Lassen $\sim 27,000$ years ago (Janik and McLaren, 2010).

The modern hydrothermal system near Lassen likely had its origin either with the onset of silicic volcanism in the Lassen area $\sim 315,000$ years ago, or as recently as 100,000 years ago (Crowley et al., 2004). Currently active steam discharge areas include Bumpass Hell (solfatara: sulfur-rich fumaroles), Sulphur Works, and Devil's Kitchen. Most are acid-sulfate, steam-heated systems, though Little Hot Springs valley shows evidence for more neutral, chlorine-rich hydrothermal fluids (Muffler et al., 1982; Thompson et al., 1985). Most of the hydrothermal waters are isotopically consistent with local meteoric waters suggesting a local source, though some signatures of Mantle-derived volatiles are observed at Sulphur Works (Janik and McLaren, 2010). Figure 1 is a map of the park, highlighting the location of the hydrothermal areas.

These currently active solfataras and other hydrothermal vents have altered the surrounding and underlying rock, which includes dacite (Sulphur Works, Bumpass Hell areas) and andesite (Devil's Kitchen). Less altered rocks are also present at a distance from the hydrothermally altered parts, allowing us to compare fresh and altered rock compositions to help reconstruct the patterns and pathways of alteration. Valley cuts expose a depth profile of the Pleistocene Brokeoff volcano fossil hydrothermal system, which altered both andesites and dacites (Janik and McLaren, 2010). This will allow us to compare ancient ( 590,000 year) and modern hydrothermal deposits to help constrain what signatures of past hydrothermal activity are most likely to be preserved, and how such deposits vary with depth. 


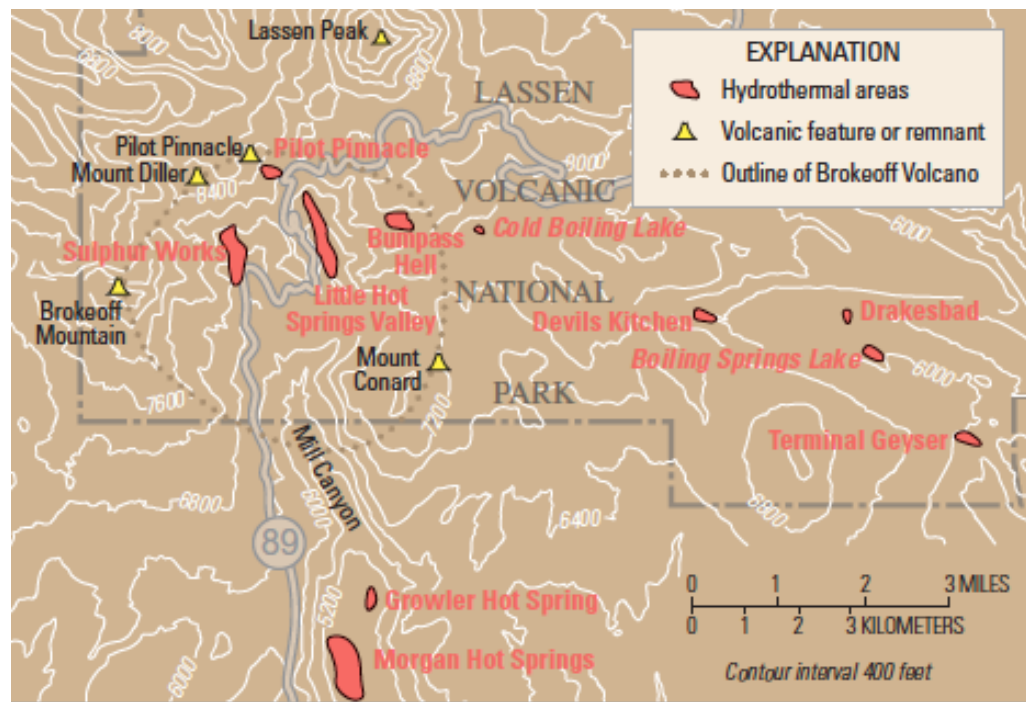

Figure 1: Map of Lassen hydrothermal field, adapted from Clynne et al., 2003.

The products of alteration in these areas include abundant hydrothermally-derived clays (montmorillonite and kaolinite), silica, and alunite (aluminum sulfate). The initial descriptions of these deposits (Day and Allen, 1925; Anderson, 1935) pre-date X-ray Diffraction, and it is likely that other minerals were not identified. Interestingly, silica-rich hydrothermally altered lavas in Lassen hydrothermal fields appear to have formed through both leaching (in acid-sulfate contexts) and precipitation of silica as a sinter (in the near-neutral, Cl-rich hydrothermal deposits: Janik and McLaren, 2010). A mineralogical and geochemical comparison between these two could help identify "fingerprints" for each environment that could be applied to sites on Mars (e.g. Gusev) where both processes have been proposed (Ruff et al., 2011).

\section{Background: Mars Hydrothermal Alteration}

The Planetary Decadal Survey (2011) recognizes the importance of Mars' hydrothermal environments: "In all epochs, the combination of volcanism and water-rich conditions might have sustained hydrothermal systems in which life could have thrived." Hydrothermal environments such as fumaroles and hot springs provide sources of heat, energy, and water for life (Walter \& Des Marais, 1993; Schulze-Markuch et al., 2007), even when it is too dry or cold for life to persist nearby. A hydrothermal origin has been proposed for some Mars surface features, including the mineralogy and geochemistry of some outcrops and soils studied by MER Spirit at Gusev (e.g. Yen et al., 2008), channels carved by flowing water that likely originated from melting of subsurface ice or release of hydrothermal fluids (e.g. Farmer et al., 1996), and potential hydrothermal mineral assemblages identified from orbit (e.g. Ehlmann et al., 2009). Chojnacki \& Hynek (2008) attribute some of the widespread Valles Marineris sulfate deposits to high temperature basalt alteration. Schulze-Makuch et al. (2007) outline targets for Martian hydrothermal environments, and Bishop et al. (2008) even propose hydrothermal activity as a possible explanation for mineralogical features of one of four finalist 2011 MSL landing sites: Mawrth Vallis. Gale Crater, the selected MSL landing site, has abundant sulfates and phyllosilicates (Milliken et al., 2010), likely formed in part by basalt alteration. Mawrth Vallis (or Nili Fossae, another potential hydrothermal site: Ehlmann et al., 2009) could be targeted for a future mission (e.g. ExoMars, Mars 2020). 
Since the surface of Mars is largely volcanic (McSween et al., 2009), evidence for hydrothermal activity lies in the alteration products and element mobility patterns produced when hydrothermal fluids interact with volcanic materials. Geochemical and mineralogical evidence can help distinguish hydrothermal from ambient temperature fluid-rock interaction, which can help reconstruct potentially habitable environments. The MER sites show evidence for hydrothermal and low temperature fluid-basalt interaction. Likely hydrothermal features have been discovered in Gusev's Columbia Hills (e.g. Schmidt et al., 2008). While Meridiani Planum has some features consistent with hydrothermal alteration (McCollom \& Hynek, 2005), it is generally interpreted as a dirty evaporite-derived eolian deposit later altered by groundwater (e.g. McLennan et al., 2005).

Hydrothermal deposits at Gusev. Deposits in outcrops and soils in Gusev's Columbia Hills are interpreted as hydrothermal because of elevated silica and Ti (likely a sinter or leached deposit) and high $\mathrm{S}, \mathrm{Cl}$, and $\mathrm{Br}$ concentrations often associated with hydrothermal fluids (Squyres et al., 2007; Schmidt et al., 2008; Yen et al., 2008). The presence of Fe-sulfate minerals and partitioning between $\mathrm{Cl}$ and $\mathrm{S}$ suggest saline-acidic hydrothermal fluids (Squyres et al., 2007, 2008), potentially fumaroles (Squyres et al., 2007; Schmidt et al., 2009) or warm liquids (Squyres et al., 2008). Water-rock interaction explains the transport of non-volatile elements (e.g. Al, Na, Fe: Squyres et al., 2008) in the Si-rich soils (e.g. Eastern valley: Morris et al., 2008), but isochemical alteration of some rocks (e.g. Watchtower: Morris et al., 2008) suggests low water-rock ratios (Wang et al., 2008), consistent with gaseous (potentially fumarolic) alteration. Ruff et al. (2011) argue that Gusev silica is not consistent with acid-sulfate fumarole leaching but rather with precipitation of a Si-rich sinter from near-neutral fluids. The extent of the Gusev alteration products is unknown since most soils were trenched from the sub-surface by Spirit's wheel and have not been detected remotely; hydrothermal deposits may thus be more widespread than orbital data would indicate (Arvidson et al., 2008). The interpretation of these deposits depends on our ability to distinguish between the products of low and high-T alteration under varied aqueous and fumarolic conditions, which can be addressed in part by studying analog environments on Earth.

\section{Methods}

Field methods. In September-October 2012, Dr. Lindsay McHenry, Ph.D. student Teri Gerard, and undergraduate student Gabrielle Walters visited Lassen Volcanic National Park. Our team first visited Sulphur Works and Bumpass Hell, two sites dominated by acid sulfate fumarolic alteration, followed by Devil's Kitchen, Boiling Springs Lake, and Drakesbad Hot Springs, which include both acid-sulfate fumarole and more neutral thermal waters. Finally, our team climbed Brokeoff Mountain to collect samples of a "fossil" hydrothermal system.

At Sulphur Works, we collected a transect of mineral precipitates with increasing distance from a fumarole vent. Yellow sulfur crystals were collected directly adjacent to where the vapors were escaping. The color and texture of the precipitates changed with distance, changing from yellow to white and grey and finally to orange away from the vent. Each mineral zone was collected in turn. Figure 2 is a photograph of this deposit. 


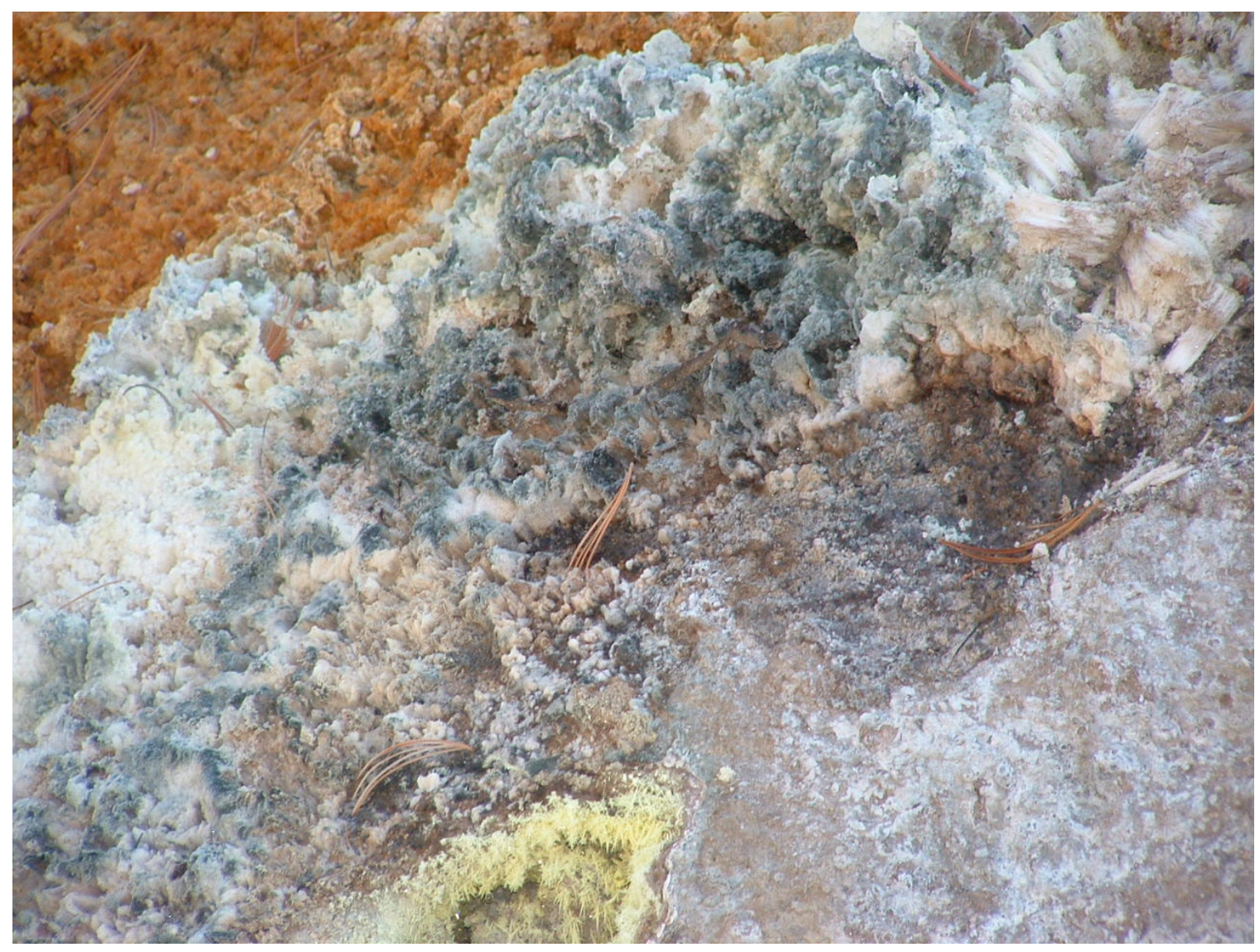

Figure 2: Sulphur Works fumarole mineral deposits. Yellow sulfur crystals (lower center) surround the vent, surrounded in turn by white and grey and then orange mineral deposits. Pine needles provide an approximate scale.

Mineral precipitate and altered rock coating samples were collected at all sites. Where such deposits were located in inaccessible or unsafe areas, a 1.6-meter pole with a can wired to the end was used to collect samples. Where possible, we measured the distance of each sample from its associated vent, or took pictures of the sampling spots with field equipment for scale. Samples were selected based on color and textural changes.

Water temperature and $\mathrm{pH}$ measurements were taken using a field $\mathrm{pH}$ probe at Sulphur Works, Bumpass Hell, Devil's Kitchen, Boiling Springs Lake, and Drakesbad Spring. Water samples were collected and filtered at Sulphur Works and Drakesbad Springs only.

Laboratory methods. Select samples were air dried and then powdered for X-Ray Diffraction (XRD) by hand using a mortar and pestle. Since soluble and temperature-sensitive sulfate minerals were anticipated, we did not use a shatterbox, micronizing mill, or heat lamp during preparation, nor did we use water or acetone to aid in the grinding process. This results in a powder that is coarser than normal for XRD analysis (and thus not suitable for quantitative phase analysis) but more likely to represent the original mineralogical composition. Each powdered sample was mounted as a random powder for analysis using a Bruker D8 Focus X-Ray Diffractometer. Samples were run using $\mathrm{Cu} \mathrm{K \alpha}$ radiation, $1 \mathrm{~s}$ per $0.02^{\circ} 2 \boldsymbol{\theta}, 2^{\circ}-60^{\circ}$ range, and a Sol-X energy dispersive detector following the methods of McHenry, 2009. 
The resulting XRD patterns were matched against the ICDD PDF database using Bruker's EVA software to identify the minerals present. Relative abundances (e.g. abundant, common, rare) were determined using relative peak heights. Amorphous silica was provisionally identified based on its characteristic "hump."

\section{Results}

Water analysis results. The results of the in-situ water analyses are reported in Table 1. Thermal and non-thermal waters covered a range of $\mathrm{pH}$ from highly acidic $(\mathrm{pH}<2)$ to near neutral, in some cases over very short distances (within 2 meters).

Table 1: Field $\mathrm{pH}$ and temperature measurements of hydrothermal waters

Site

Description $\quad \mathrm{pH} \quad \mathrm{T}\left({ }^{\circ} \mathrm{C}\right) \quad$ Sample?

Sulphur Works

$\begin{array}{llll}\text { bubbling pool } & 2.08 & 68.5 & \text { Yes } \\ \text { nearby stream } & 6.90 & 12.0 & \text { Yes }\end{array}$

Bumpass Hell

bubbling pond $\quad$\begin{tabular}{ll}
$2.45 \quad 81.0$ \\
\hline
\end{tabular}

aqua colored pond $\quad 3.00 \quad 15.5$

Devil's Kitchen

\begin{tabular}{lll}
\hline boiling clear water & 6.40 & 93.4 \\
nearby milky water & 2.30 & 86.1 \\
bubbling muddy pool & 5.82 & 75.5
\end{tabular}

Boiling Springs Lake

$\begin{array}{lll}\text { W edge of clear lake } & 1.88 & 46.0 \\ \text { clear boiling pot } & 2.93 & 86.5 \\ \text { boiling mud pot } & 3.84 & 87.0 \\ \text { S edge of clear lake } & 2.34 & 49.0\end{array}$

Drakesbad Hot Spring
Warm stream
$6.79 \quad 56.0 \quad$ Yes

X-ray diffraction results. The results of the preliminary XRD study are presented in Table 2. Sulfur-bearing minerals are ubiquitous in all samples but SW-12-2, which is a sample of altered substrate. Elemental sulfur is present in samples from Sulphur Works, Bumpass Hell, and Devil's Kitchen, generally near the center of the fumarole where they form in direct contact with the fumarolic vapors. Sulfate minerals become more abundant with distance from the direct vapors, and include Fe-sulfates (jarosite, rhomboclase), Al-sulfates (alunite, alunogen), and mixed sulfates (natroalunite). Calcite and the Ca-sulfate mineral gypsum were so far only 
observed in the coating from a rock in the stream at Drakesbad Hot Spring. The Fe-sulfide minerals pyrite and marcasite were so far only observed at Bumpass Hell, and indicate reducing conditions in the stream water at that site. The "rotten egg" smell at Bumpass Hell is consistent with $\mathrm{H}_{2} \mathrm{~S}$ gas rather than $\mathrm{SO}_{2}$, which is also consistent with more reducing conditions.

Table 2: Mineral assemblages, based on X-Ray Diffraction

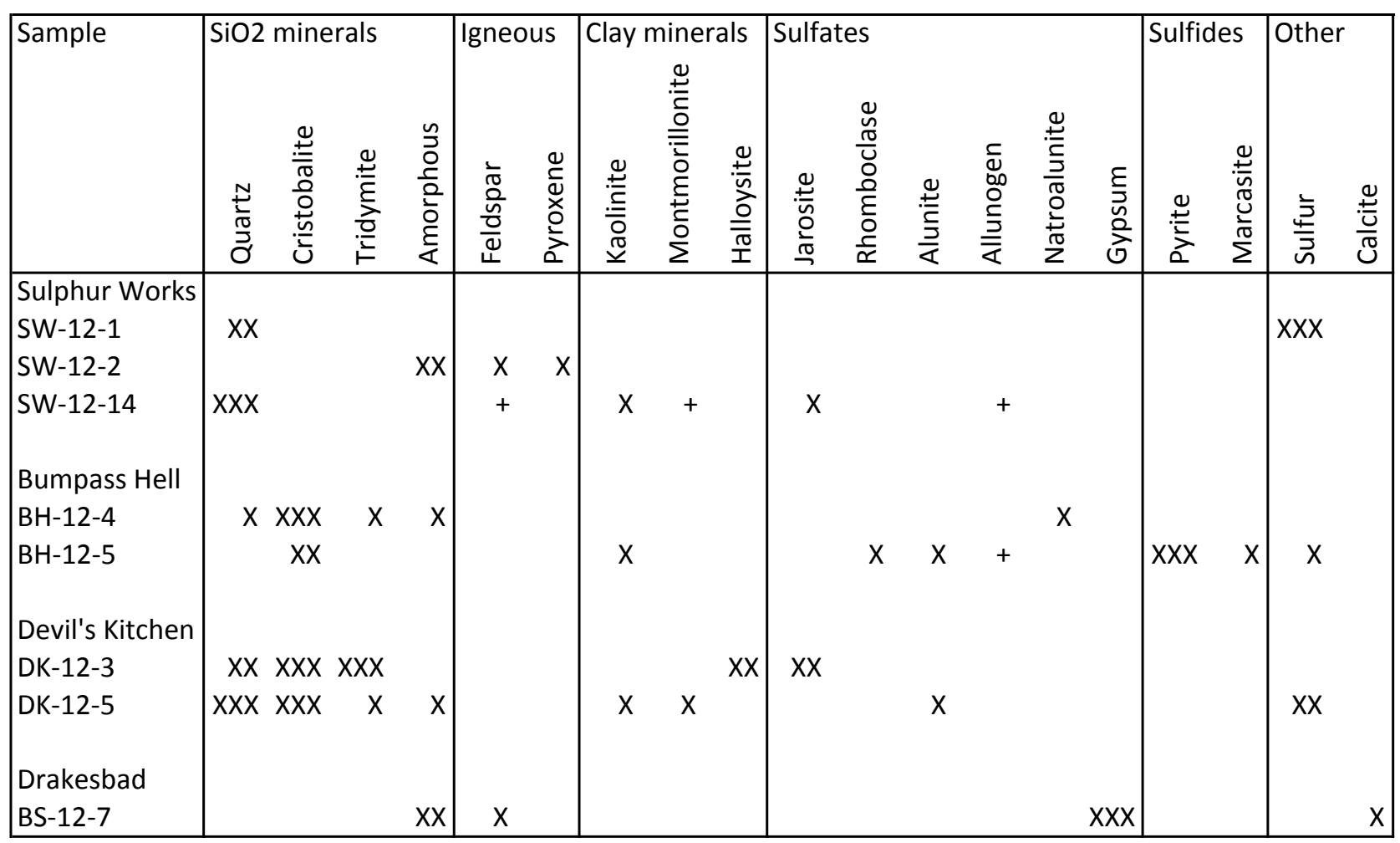

$\mathrm{XXX}=$ abundant, $\mathrm{XX}=$ common, $\mathrm{X}=$ rare to common, $+=$ rare .

Clay minerals were observed in samples from Sulphur Works, Bumpass Hell, and Devil's Kitchen. Halloysite and kaolinite are typical alteration products formed by acid hydrothermal leaching of feldspars or other igneous minerals, while montmorillonite (a smectite) can form under a wider range of conditions.

The $\mathrm{SiO}_{2}$ mineral assemblage varied considerably between samples, including quartz, tridymite, cristobalite, and an amorphous phase likely consistent with amorphous silica. While quartz could be a primary igneous component of the dacitic substrate, the fact that it is not observed in the samples that yielded feldspars and pyroxenes (other primary dacitic constituents) makes it more likely related to the secondary and precipitated minerals. Cristobalite and tridymite are also phases associated with altered volcanics.

Amorphous silica can form during hydrothermal alteration, either by leaching under acidic conditions or direct precipitation under neutral sinter conditions (e.g. Ruff et al., 2011). It is likely that both processes took place in the Lassen hydrothermal system (e.g. Janik and McLaren, 2010); the amorphous phase in the altered substrate sample from Sulphur Works likely formed by acid-sulfate leaching, while the amorphous phase in the rock coating at Drakesbad probably 
resulted from sinter precipitation. Future Scanning Electron Microscopy (SEM) analysis of these samples will help confirm the presence of amorphous silica (as opposed to glass or another amorphous phase).

\section{Future Work}

We will continue to analyze our 2012 samples by XRD to determine spatial patterns of alteration and precipitation around Lassen fumaroles. We will additionally analyze select samples by X-ray Fluorescence (XRF) Spectroscopy to determine their major and minor element compositions, tracking changes in bulk composition between more and less altered samples. Select samples will also be analyzed by SEM to help identify amorphous phases (such as amorphous silica or glass) and determine the textural relationships between the different minerals within samples, particularly in sample coatings and crusts.

In September-October 2013 we will visit Lassen Volcanic National Park a second time. We will re-visit Bumpass Hell and Devil's Kitchen to collect additional mineral and water samples, and will also visit Little Hot Springs Valley to expand our collection of near-neutral sinter deposits and associated water.

Once we have completed the field and laboratory phases of this project, we will assess which environmental parameters (e.g. temperature, $\mathrm{pH}$, water composition, substrate composition) exert the greatest influence on the resulting alteration mineralogy and geochemistry, identifying "signatures" of specific conditions. This data, and our interpretations, will then be compared to published mineral and geochemical interpretations for potential Martian hydrothermal deposits (e.g. at Columbia Hills, Gusev Crater).

\section{References}

Arvidson, R.E., et al., 2008. Spirit Mars rover mission to the Columbia Hills, Gusev Crater: Mission overview and selected results from the Cumberland Ridge to Home Plate. JGR 113: E12S33.

Anderson, C.A., 1935. Alteration of the lavas surrounding the hot springs in Lassen Volcanic National Park. American Mineralogist 20: 242-253.

Bibring, J.-P., et al. (2005). Mars surface diversity as revealed by the OMEGA/Mars Express observations. Science 307: 1576-1581.

Bishop, J.L. et al., 2008. Phyllosilicate diversity and past aqueous activity revealed at Mawrth Vallis, Mars. Science 321: 830-833.

Chojnacki, M., Hynek, B.M., 2008. Geological context of water-altered minerals in Valles Marineris, Mars. JGR 113: E12005.

Clynne, M.A., Janik, C.J., Muffler, L.J.P., 2003. "Hot water" in Lassen Volcanic National ParkFumaroles, steaming gound, and boiling mudpots. U.S. Geological Survey Fact Sheet 101-02. 
Crowley, J.K., Mars, J.C., John, D.A., Muffler, L.J.P., Clynne, M.A., 2004. Hydrothermal mineral zoning within an eroded stratocone: remote sensing spectral analysis of Brokeoff Volcano, California. In: King, P.L., Ramsey, M.S., Swayze, G.A. (Eds.), Infrared Spectroscopy in Geochemistry, Exploration Geochemistry, and Remote Sensing. Mineralogical Association of Canada Short Course, vol. 33. Ontario, London, pp. 215226.

Day, A.L., Allen, E.T., 1925. The Volcanic Activity and Hot Springs of Lassen Peak. The Carnegie Institution of Washington, Washington, 190pp.

Ehlmann, B.L., et al., 2009. Identification of hydrated silicate minerals on Mars using MROCRISM: Geologic context near Nili Fossae and implications for aqueous alteration. JGR 114: E00D08.

Farmer, J.D., 1996. Hydrothermal systems on Mars: an assessment of present evidence. In: Bock, G. Goode, J. (eds.), Evolution of Hydrothermal Ecosystems on Earth (and Mars?). Wiley, NY. 273-299.

Janik, C.J., LcLaren, M.K., 2010. Seismicity and fluid geochemistry at Lassen Volcanic National Park, California: Evidence for two circulation cells in the hydrothermal system. Journal of Volcanology and Geothermal Research 189: 257-277.

John, D.A., Briet, G.N., Lee, R.G., Diles, J.H., Muffler, L.P., Clynne, M.A., 2004. Fossil magmatic-hydrothermal systems in Pleistocene Brokeoff volcano, Lassen Volcanic National Park, California. Eos Trans. AGU, 87(52), Fall Meet. Suppl., Abstract V53A-1745.

McCollom, T.M., Marcucci, E, Hynek, B.M., 2010. Combined experimental and theoretical study of acid-sulfate alteration of basalt for interpretation of sulfate-rich deposits on mars, $41^{\text {st }}$ Lunar and Planetary Science Conference, abstract 1380.

McHenry, L.J., 2009. Element mobility during zeolitic and argillic alteration of volcanic ash in a closed-basin lacustrine environment: Case study Olduvai Gorge, Tanzania. Chemical Geology 265, 540-552, doi: 10.1016/j.chemgeo.2009.05.019

McLennan, S.M., et al., 2005. Provenance and diagenesis of the evaporite-bearing Burns formation, Meridiani Planum, Mars. EPSL 240: 95-121.

McSween, H.Y.J., Taylor, G.J., Wyatt, M.B., 2009. Elemental composition of the Martian crust. Science 324: 736-739.

Milliken, R.E., Grotzinger, J.P., Thomson, B.J, .2010. Paleoclimate of Mars as captured by the stratigraphic record in Gale Crater. GRL 37: L04201.

Morris, R.V., et al., 2008. Iron mineralogy and aqueous alteration from Husband Hill through Home Plate at Gusev Crater, Mars: Results from the Mössbauer instrument on the Spirit Mars Exploration Rover. JGR 113: E12S42. 
Muffler, L.J.P., Nehring, N.L., Truesdell, A.H., Janik, C.J., Clynne, M.A., Thompson, J.M., 1982. The Lassen Geothermal System. Proceedings of the Pacific Geothermal Conference 1982. University of Auckland, New Zealand, pp. 349-356.

Murchie, S.L., et al. (2009). A synthesis of Martian aqueous mineralogy after 1 Mars year of observations from the Mars Reconnaissance Orbiter, Journal of Geophysical Research 114: E00D06.

National Research Council (NRC), Committee on the Planetary Science Decadal Survey, 2011. Vision and voyages for planetary science in the decade 2013-2022. The National Academies Press, Washington, D.C., 400 pages.

Ruff, S.W. et al., 2011. Characteristics, distribution, origin, and significance of opaline silica observed by the Spirit rover in Gusev crater, Mars. Journal of Geophysical Research 116: E00F23.

Schmidt, M.E., et al., 2009. Spectral, mineralogical, and geochemical variations across Home Plate, Gusev Crater, Mars indicate high and low temperature alteration. Earth and Planetary Science Letters 281: 258-266.

Schmidt, M.E., Ruff, S.W., McCoy, T. J., Farrand, W.H., Johnson, J.R., Gellert, R., Ming, D.W., Morris, R.V., Cabrol, N.A., Lewis, K.W., Schröder, C., 2008. Hydrothermal origin of halogens at Home Plate, Gusev Crater. JGR 113: E06S12.

Schulze-Makuch, D. et al., 2007. Exploration of hydrothermal targets on Mars. Icarus 189: 308324.

Squyres, S.W., et al., 2008. Detection of silica-rich deposits on Mars. Science 320: 1063-1067. Squyres, S.W., et al., 2007. Pyroclastic activity at Home Plate in Gusev Crater, Mars. Science 316: 738-742.

Thompson, J.M., 1985. Chemistry of thermal and nonthermal springs in the vicinity of Lassen Volcanic National Park. Journal of Volcanology Geothermal Research 25: 81-104.

Walter, M.R., Des Marais, D.J., 1993. Preservation of biological information in thermal spring deposits: developing a strategy for the search for fossil life on Mars. Icarus 101: 129-143.

Wang, A., et al., 2008. Light-toned salty soils and coexisting Si-rich species discovered by the Mars Exploration Rover Spirit in Columbia Hills. JGR 113: E12S40.

Yen, A.S., et al., 2008. Hydrothermal processes at Gusev Crater: An evaluation of Paso Robles class soils. JGR 113: E06S10. 